\title{
On Line Crime Records Management System: A Case of Pakistan
}

\author{
Saqib Nawaz ${ }^{1}$ Junaid Ghaffar ${ }^{2} \quad$ Asif Siddique $^{2} \quad$ Muhammad Aslam ${ }^{2}$ \\ 1.Department of Computer Science, Institute of Southern Punjab, Multan, Pakistan \\ 2. Department of Computer Science \& IT, Ghazi University, Dera Ghazi Khan, Pakistan
}

\begin{abstract}
The Crime Management and Reporting System apply to Police Stations all across the country .It specifically looks into the Crime detection and prevention. Conviction of criminals depend a highly responsive backbone of Information Management. The efficiency of the police and the effectiveness with which it tackles crime depend on what quality of information it can derive from its existing records and how fast it can have access to it. The different modules of this project are wanted module, complaint module, noc module, province module, city module, union council module and Administrators module. Each of the must first register with the software. For the registration part each enter their details like user name, address, phone number, and get a user Id from the software. All these are done in the module. The crime module is used for entering all detail about the crime. It consists of the date and time, place, type of crime, location of the crime, police station where it is recorded etc. File System is a system used to report crimes. It can used to report crime. This project is mainly useful for police stations. This system will help to manage all the activities in a police station using computers by computerizing all the activities inside a police station can be managed easily.
\end{abstract}

Keywords: Crime management, Crime Records, Police Stations, Web Applications

DOI: $10.7176 /$ JIEA/9-6-02

Publication date:October $31^{\text {st }} 2019$

\section{Introduction}

This project is aimed to develop a crime file for maintain a computer records of all the wanted against crime. The system is online website to access throughout the police department. the user add online complaint and the complaint register to admin when the admin see the complaint data where the complaint register which city and province the province and city already add the admin the user are easy select the province, city and union council [1].

This system is named as Online Crime Management System. This system is made to keep the records about the wanted and about the crimes. It is very useful as the written papers have a limited time period and can get lost but in crime management system this is not possible as a backup file will be created automatically and also updated the record.

It is an era of computerized and data security to combat with increasing rate of crimes and criminal. This is web based application that provides managing data and various information about the criminals and crimes not only this but also provides the information and current status using html, css, php, ajax.j.query.mysqI [2].

The system is when the admin check the criminal background data and they check the new complain and wanted and the user download the Performa online.

This system can be used as an online crime file to the police department to manage the records and different activity of related to first information report. In such online crime file system we will manage all such activity like registration of complaint updating information this system will provide better prospective for the enhancement of organization regarding to quality and transparency.

We want to design a system for the proper recording of criminal activities that will enable storage, retrieval and security of criminal information. The use of manual process using paper files in the documentation of criminal information. as we know manual systems are quite tedious, time consuming and less efficient and accurate in comparison to the computerized system [3].

The product provides a framework within which a user can easily work with. That was out next objective. We know users are of many categories, like users from who know working with computers very well to users who did not know about computers. so all the category can use the software so it should be user friendly. The product provides a framework, which is error free. We know a crime management system is actually a critical process having many calculations and operations. So each simple error laid to big problem. so it should be error free and our objective is to build error free software. The software is made to work efficiently and effectively. It results in regular and timely action against crime reported. It can be observed that the information can be obtained easily and accurately.

\section{Literature}

Crime Management System is design to transform the manual way of searching, sorting, keeping and accessing crime information (files) into design of record will be a solution to the problem being experienced by the current 
manual method of keeping. Some of the previous of is now being implemented in Pakistan also, with large police station like KPK and Other cities. A resource and based on real-time data capture and intelligent decision. The purpose of writing this was to find out how in various police station work and compare it to my system [4].

\subsection{Existing systems}

Today is a information technology age computer field growing up and in all field of life computer used is to become necessary and now a day's hundred of the inventory system existing in market these systems have maximum functionality are same and some have different functionalities and highly function so that's why these can be used by sophisticated and expert users those are difficult and more typical to use for a inexpert user. There are following existing systems percent in market which I visits and study and analysis personally after which I propose my system [5].

\subsubsection{Existing System1}

I visited many websites for crime management system .This system is based on visual basic and simple code. The scope and functionality is that this system registers the only Add complaint, details.

\subsubsection{Existing system}

The police station currently uses manual system for management and maintenance of the recorded. In this current system all record maintained on paper in every field of the police station. The information may be incomplete or not follow the standard of management [6].

\subsection{Proposed system}

The working in the organization will be well planned and organized. The data will be stored properly in data stores, which will help in retrieval of Information as well as its storage.

\section{Accuracy}

The level of accuracy in the proposed system will be higher. All operation would be done Correctly and it ensures that whatever information is coming from the center is accurate [7].

\section{Reliability}

The reliability of the proposed system will be high due to the above stated Reasons. The reason for the increased reliability of the system is that now there would be proper storage and access to information [8].

\section{No Redundancy}

In the proposed system utmost care would be that no information is repeated anywhere, in storage or otherwise. This would assure economic use of storage space and consistency in the data stored.

\section{Less human error}

No one is perfect, and we are all prone to making mistakes. This is why a machine that performs repeated tasks is less likely to make mistakes than an employee. Immediate storage of Information

In manual system, there are many Problems to store the largest amount of information.

\section{Easy to Operate}

The system should be easy to operate and should be such that it can be developed within a short period and fit in the limited budget of the user.

The police station currently use manual system for management and maintenance of the record. In this current system all record maintained on paper in every field of the police station. The information may be incomplete or not follow the standard of management. Inconsistency occurs due to the multiple copies of the same data.

Today is a computer and when develop the software on line crime management sytem. This sytem work is easy and data storage of all wanted. They are the best for paperwork.computer work on every field and they use easy to operate.

\subsection{Interview}

The most common technique for gathering information about system is to sit down with the policestation and ask them what they need. The discussion should be planned out ahead of time based on the type of requirements you're looking for. There are many good ways to plan

the interview, but generally you want to ask open-ended questions to get the interviewee to start talking and then ask questions to uncover requirements.

\subsection{FEASIBILITY Report}

A feasibility study is a test of system proposal according to its workability, impact on the organization, ability to meet user needs and effective use of resources. The objective of feasibility study is not to solve the problem, but to acquire a sense of its scope. During the study, the problem definition is crystallized and aspects of the problem to be included in the system are determined, consequently costs and benefits are estimated with greater 
detail at this stage. The result of the feasibility study is a system formal proposal. This is simply a form of documenting or detailing nature and scope of proposed solutions . The proposal summarizes what is known and what is going to be done. Three points for feasibility report. Technical feasibility Economic feasibility Behavior feasibility 2.6.1 Technical Feasibility: The feasibility center on the existing computer system (software, hardware) and to what extend it can support the proposed addition. In the proposed system, data can be easily stored and managed in database management system software. The results for various queries can be generated easily. Therefore, the system is technically feasible.

Pantium4 computer are easily available in market at low cost with one GB RAM and 250GB hard disc and. These equipments have the technical capacity to perform our required operation which we will develop in our purposed system. The proposed system provide technically reliability, ease of access and data security. System will upgrade after some time.

\subsection{Spiral model}

Makes use of both waterfall and prototype models. It adds 4th generation programming languages, rapid application development prototyping and risk analysis to the waterfall model. The system requirements are designed and a preliminary system design is created. An initial prototype is designed and tested. The system is created based on the final prototype. The final system is evaluated and tested. Though this model reduces risk to a large extent, it may not meet the budget and is applied differently for each application. rapid application development prototyping and risk analysis to the waterfall model. The system requirements are designed and a preliminary system design is created.

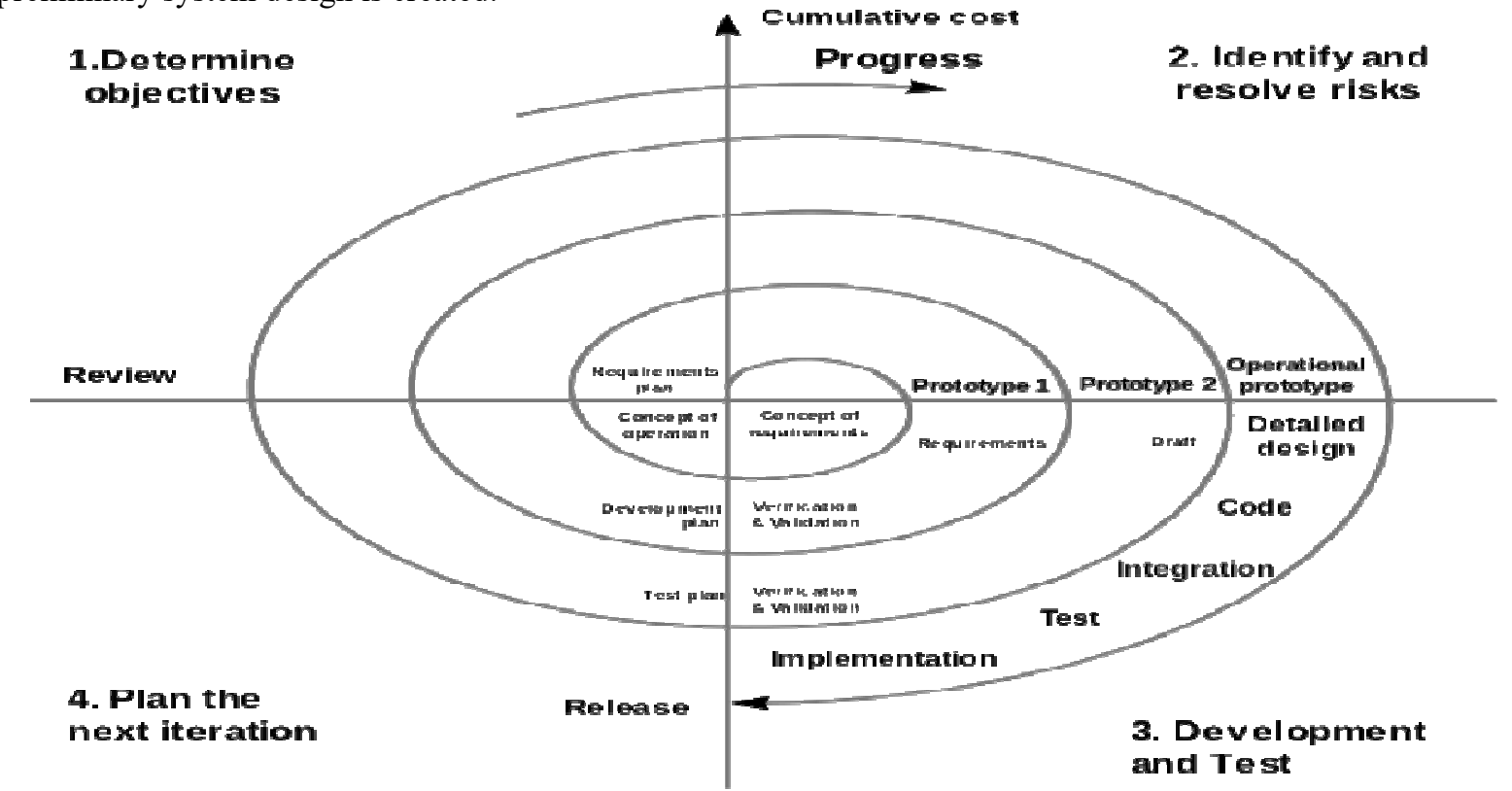

Figure 1: spiral model 


\subsection{ERD (Entity relationship Diagram):}

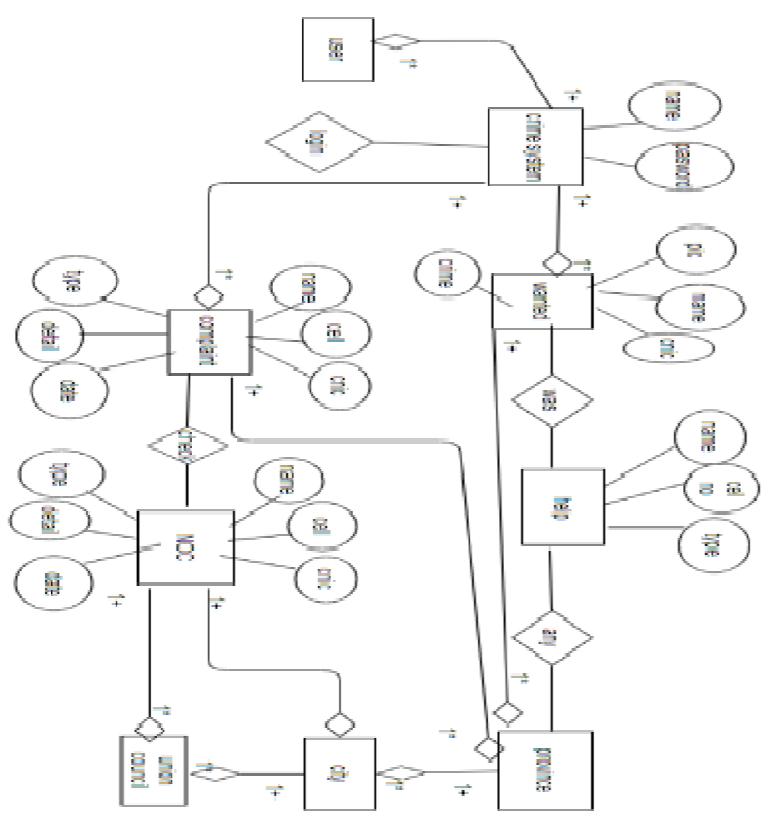

Figure 2: ERD(Entity Relationship Diagram)

\section{Design}

\subsection{Entities}

Which are represented by rectangles. An entity is an object or concept about which you want to store information. A weak entity is an entity that must defined by a foreign key relationship with another entity as it cannot be uniquely identified by its own attributes alone.

\subsection{Attributes}

Which are represented by ovals. A key attribute is the unique, distinguishing characteristic of the entity. For example, an employee's social security number might be the employee's key attribute.

\section{Development of program}

\section{Problem Definition}

In this phase we define the problem statement and decide the boundries of the problem. In this phase we understand the problem. What is our requirement and what should be the output of the problem solution.

\section{Problem Definition:}

In this phase we determine the requirement like variable, functions etc to solve the problem. That mean we gather the required resource to solve the problem

\section{Algorithm development:}

We develop a step by step procedure to solve the problem using the specification given in the previous phase. This phase is very important for program development. That means we write the solution in step by step statement.

\section{Code and Documentation:}

This phase uses a programming language to write or implement actual programming instructions for the steps defined in the previous phase. In this phase, we construct actual program. That means we write the program to solve the given problem using programming languages like $\mathrm{C}, \mathrm{C}++$, Java etc.,

\section{Testing and debugging:}

During this phase, we check whether the code written in previous step is solving the specified problem or not. That means we test the program whether it is solving the problem for various input data values or not. We also test that whether it is providing the desired output or not.

\section{Maintenance:}

During this phase, the program is actively used by the users. If any enhancements found in this phase, all the phases are to be repeated again to make the enhancements. That means in this phase, the solution (program) is used by the end user. 


\subsection{Tool selection \\ 4.1.1 Hardware Requirement \\ - Processor : Intel Core i5-4210U $1.7 \mathrm{GHz}$ \\ - RAM : 4GB \\ - Storage : $1 \mathrm{~GB}$ \\ - System type : 64-bit operating system \\ - Display : For all devices \\ 4.1.2 Software Requirement \\ - Web server : Apache/XAMPP \\ - IDE : Dreamweaver 8/Sublime Text3 \\ - Database : MY SQL \\ - Browser : Google Chrome, Mozilla Firefox}

\subsection{Platform selection}

The web platform choose matters greatly in terms of website functionality and compatibility with requirements or existing systems. Budget, site administration, and technical requirements should also be considered.

Develop the system web language(HTML,CSS,PHP)they work only web browers (chrome, mozillaf firefox) the connect the database and the user easily understand and reliable the admin select the platform on web they work easily and develop the system.the system are useful for future new technologies are develop more then paper work .when litte technologies are use in project for future scope.some mudule are added for developing the project.

\subsection{Language}

PHP is one among the popular programming languages. PHP is probably the most popular web development language right now. Therefore,Php Trainingis essential to become a successful Php Developer. At least 20 Million Domains use PHP and it's the language used on major sites such as Wikipedia and Facebook as well as in some of the world's biggest open source projects like WordPress.

Html:

HTML or Hyper Text Markup Language is the standard markup language used to create web pages. HTML is written in the form of HTML elements consisting of tags enclosed in angle brackets (like $<\mathrm{html}>$ ). HTML tags most commonly come in pairs like $<\mathrm{h} 1>$ and $</ \mathrm{h} 1>$, although some tags represent empty elements and so are unpaired, for example $<i m g>$. The first tag in a pair is the start tag, and the second tag is the end tag (they are also called opening tags and closingtag). The purpose of a web browser is to read HTML documents and compose them into visible or audible web pages. The browser does not display the HTML tags, but uses the tags to interpret the content of the page.

PHP:

Hypertext Preprocessor or simply php is a server-side scripting language Designed for Web development, but also used as a general programming language. PHP code may also be executed with a command-line interface and can be used to implement standalone graphical applications. You can easily search how to learn PHP language because PHP is most widely used language all around the world. You can easily find documentation online on PHP for free because it is open source and free. That is why it is one of the reasons that PHP is the best programming language for website development. PHP is the scripting language with the largest user base. They are fully geared with the latest technological updates and tools and provide future-proof and scalable solutions to create robust platforms for your web presence.

With our PHP developers by your side, you get instant access to:

\section{Test Results:}

Few results are shown below 


\section{Admin Login}

PIoaso cnter your Namo and password

\section{MAME}

PASSWDRD

\section{1 ogun}

\section{DFEIGN EY SACRIBNAWAV}

Fig 1. Login successfully

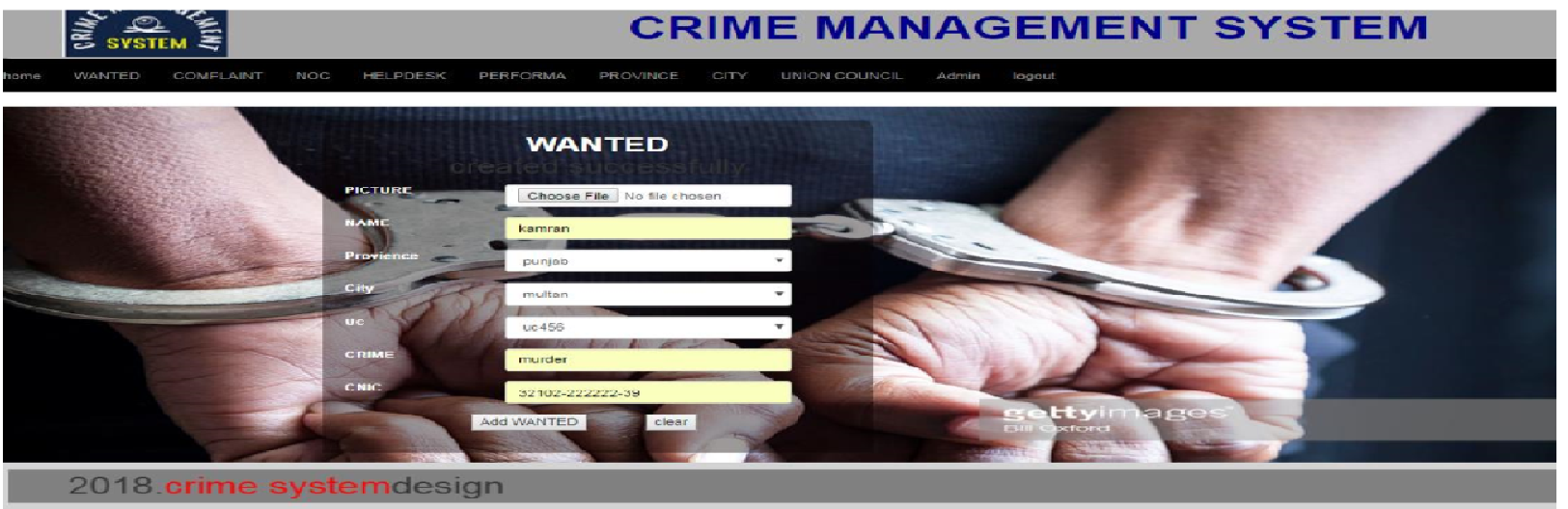

Fig 2. Wanted

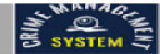

CRIME MANAGEMENT SYSTEM

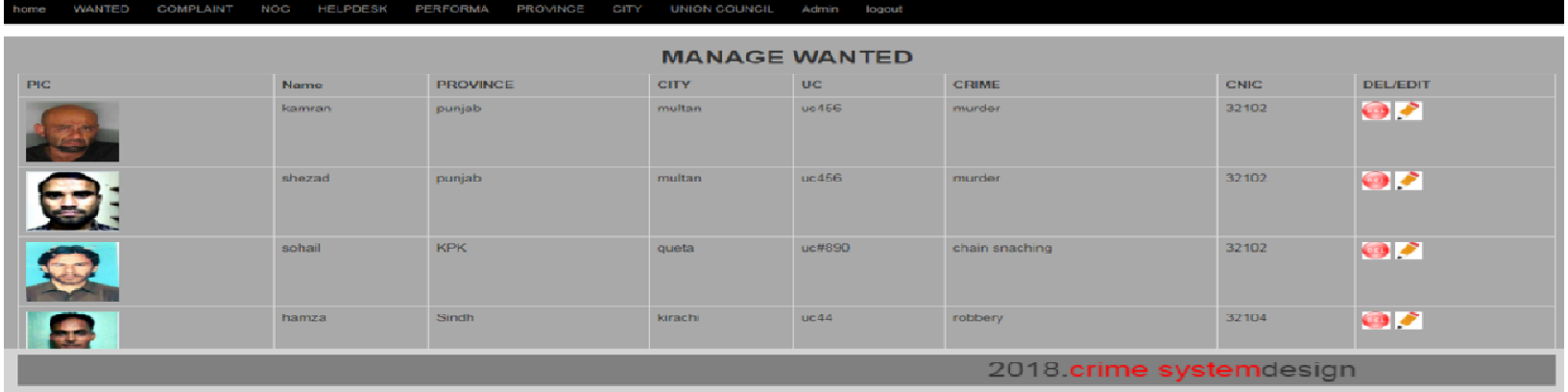

Figure 3: Add wanted 


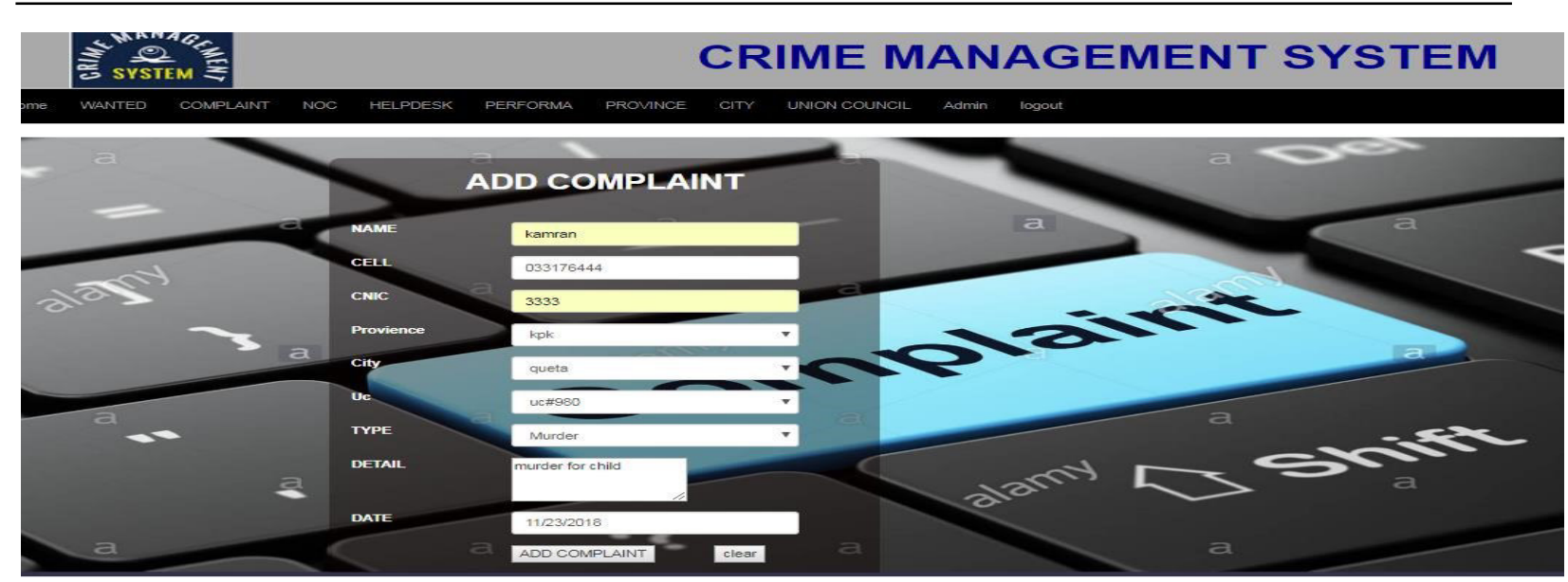

Fig 4. Add complaint

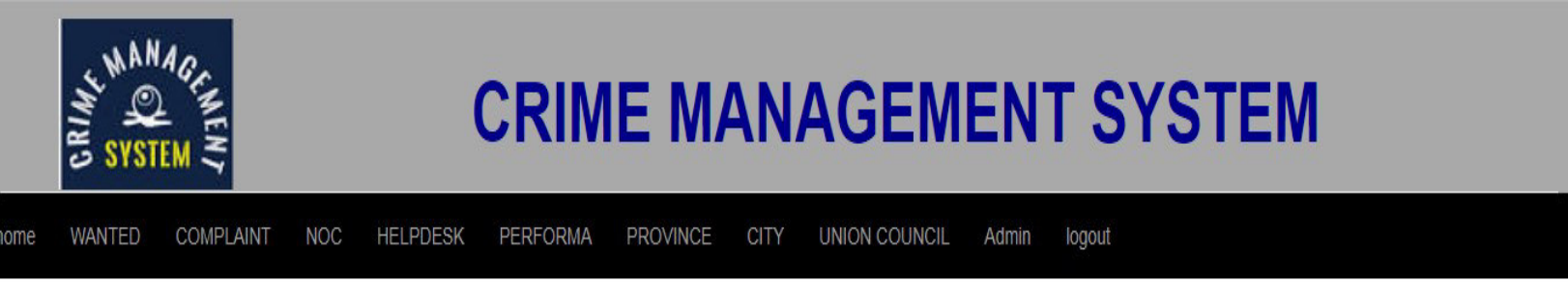

\begin{tabular}{|c|c|c|c|c|c|c|c|c|c|}
\hline \multicolumn{10}{|c|}{ MANAGE COMPLAINT } \\
\hline NAME & CELL & CNIC & PROVINCE & CITY & UC & TYPE & DETALL & DATE & DEL/EDIT \\
\hline saqib & 2222 & 4567 & punjab & multan & uc\#980 & Murder & eee & 2018-11-11 & (01) \\
\hline kamran & 4567 & 78999 & sindh & kirachi & uc $\$ 90$ & Murder & murder in child & 2018-12-23 & (0.1) \\
\hline
\end{tabular}

Fig 5. Manage complaint

\section{CRIME MANAGEMENT SYSTEM}

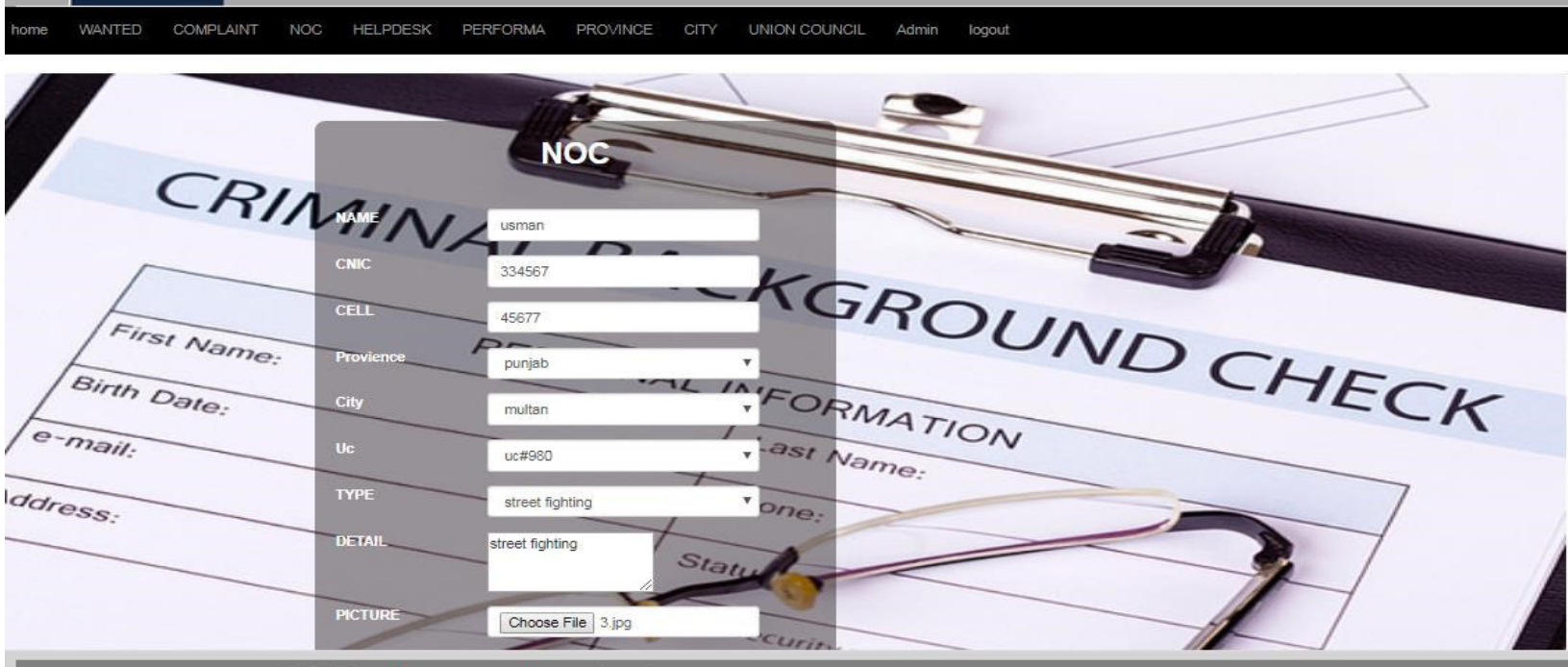

Fig 6. NOC 
7

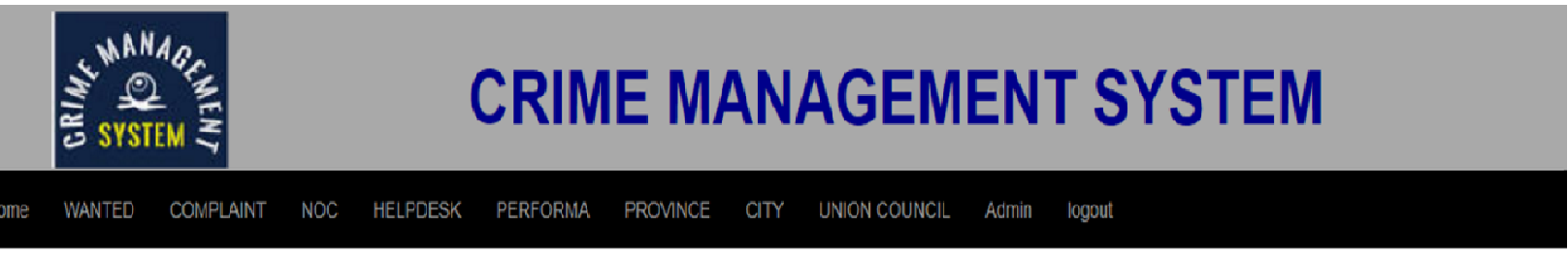

\begin{tabular}{|c|c|c|c|c|c|c|c|c|c|}
\hline \multicolumn{10}{|c|}{ MANAGE NOC } \\
\hline NAME & $\mathrm{CNIC}$ & CELL & PROVINCE & $\mathrm{CITY}$ & UC & TYPE & DETAIL & PIC & DEL/EDIT \\
\hline saqib & 4567 & 2222 & punjab & multan & uc $\# 980$ & Murder & $\theta \theta \theta$ & & (0:2) $\mathrm{A}$ \\
\hline usman & 334567 & 45677 & punjab & multan & uc $\# 980$ & street fighting & fighting & & (014) 1 \\
\hline
\end{tabular}

Fig 7.Add NOC
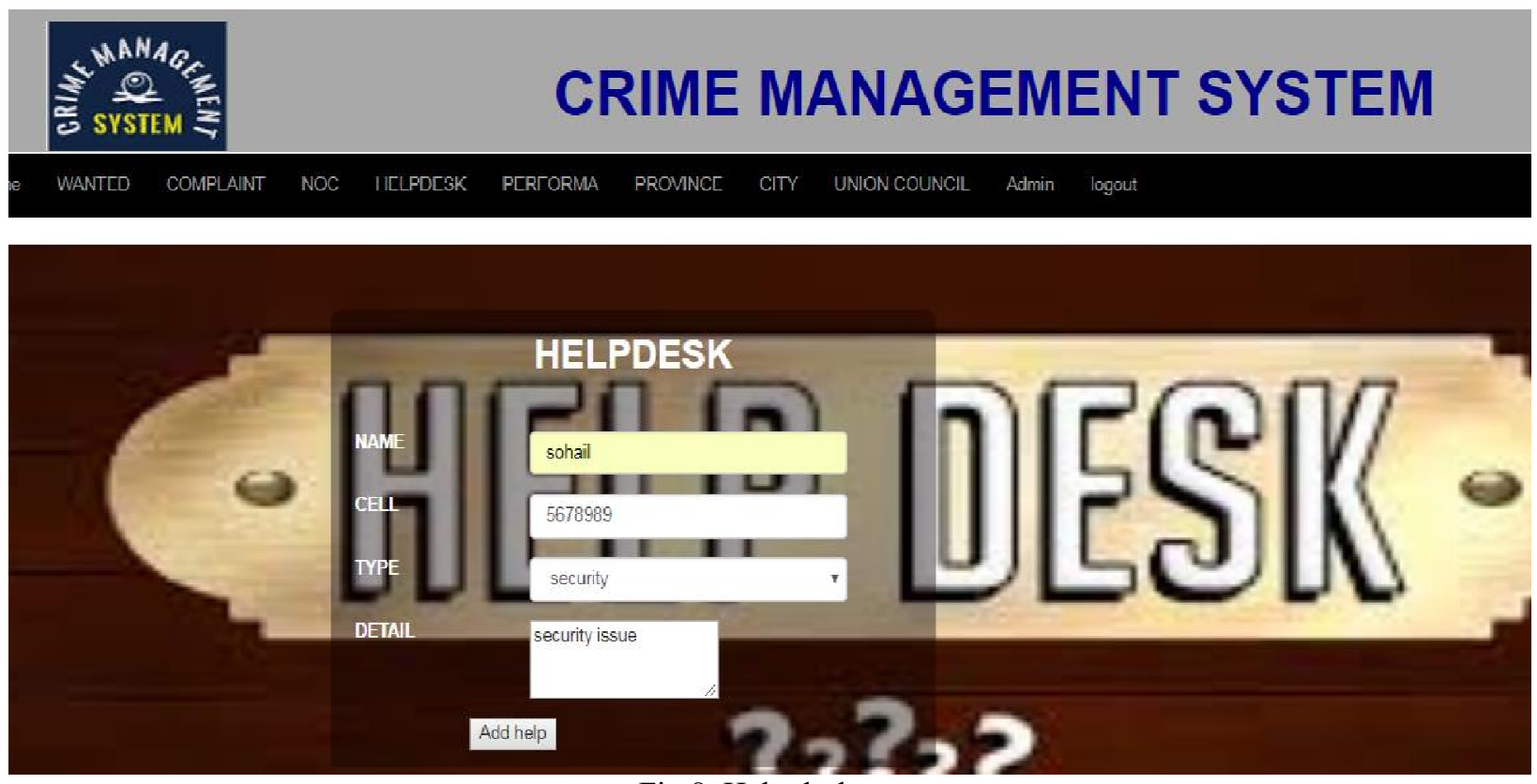

Fig 8. Help desk 


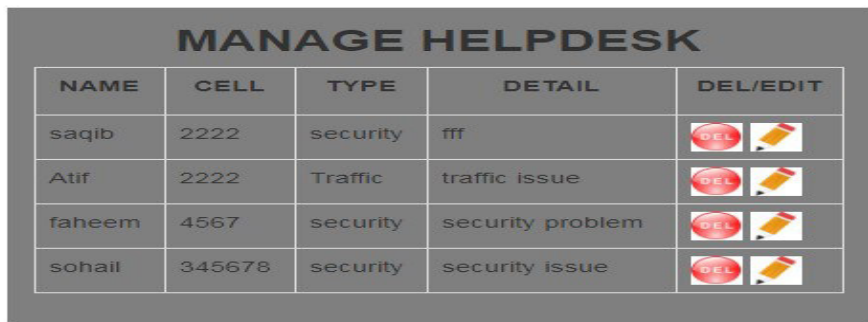

Fig 9: Manage helpdesk

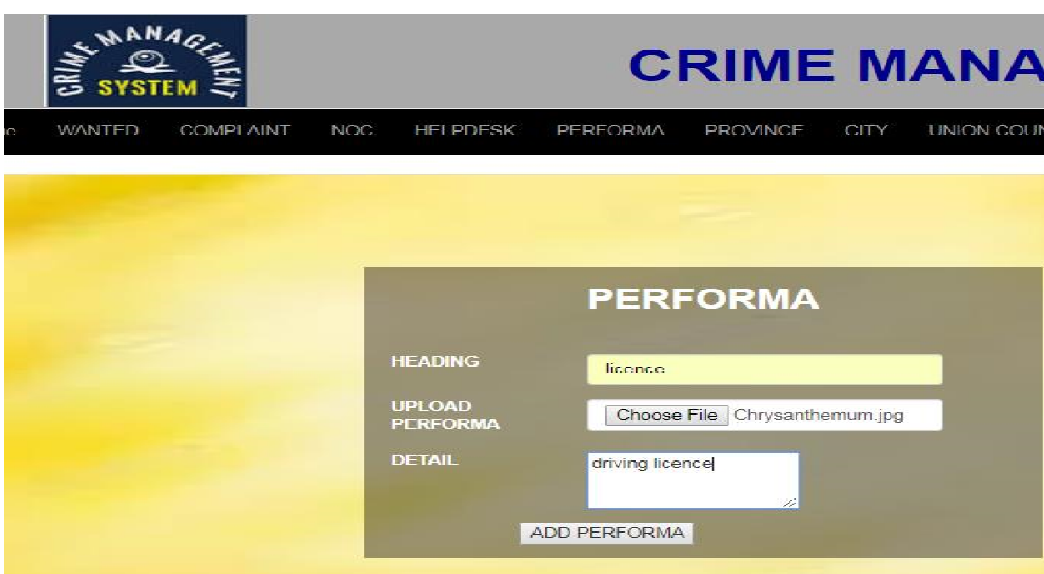

Fig 10. Performa

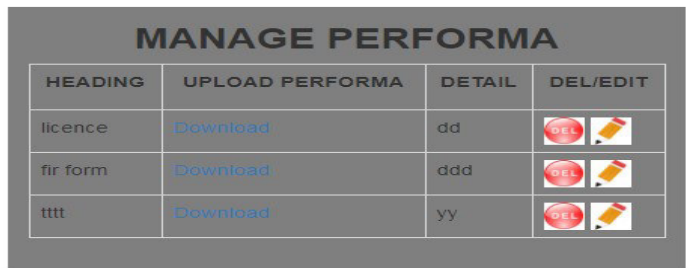

Fig 11: Manage Performa 


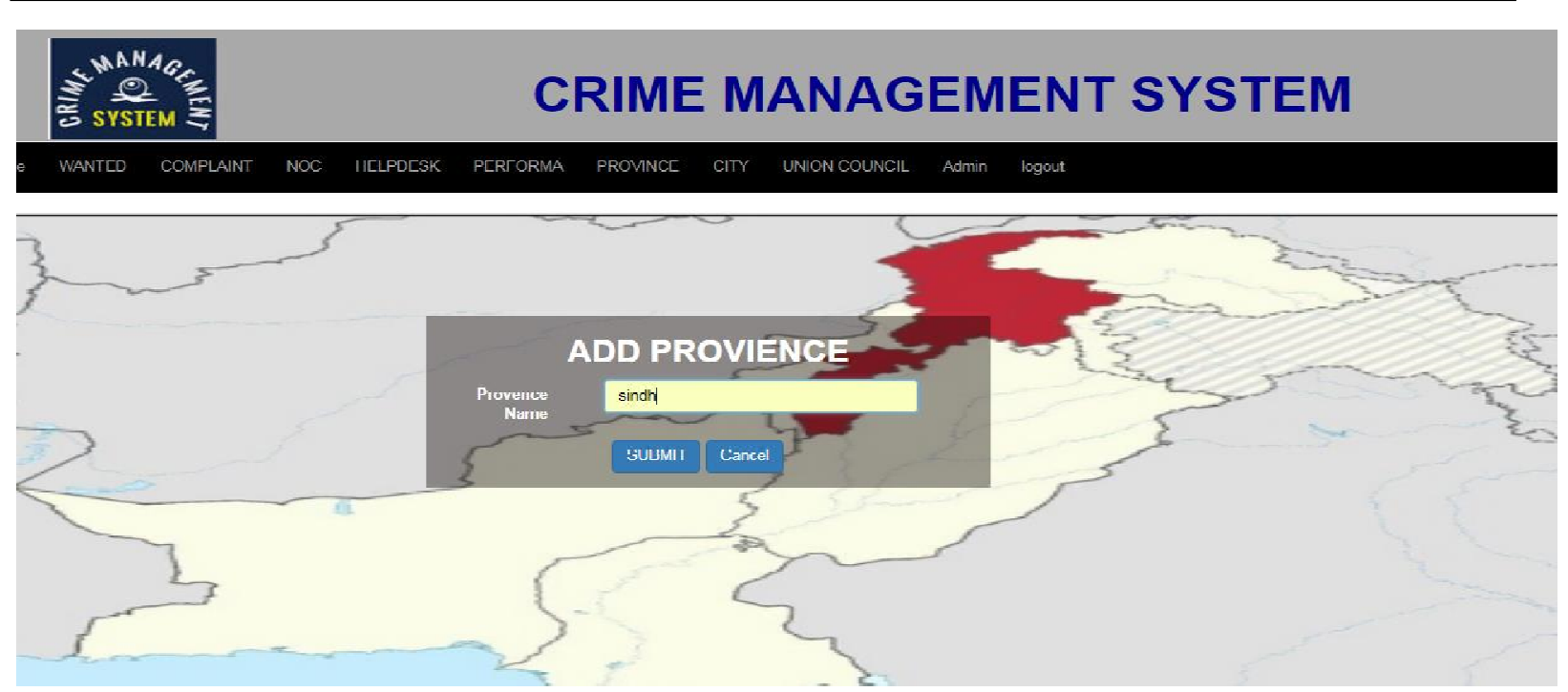

Fig 12. Add province

\section{CRIME MANAGEMENT SYSTEM}

home WANTED COMPLANT NOC HELPDESK PERFORMA PROUNCE CITY UNONCOUNCIL Admin logovil

$\begin{array}{lc} & \text { MANAGE PROVIENCE } \\ & \text { DELLEDIT } \\ \text { provience_name } & 0 ! \\ \text { punjabo } & 0 ! \\ \text { kpk } & 0 ! \\ \text { sindh } & 0 ! \\ \text { Balochistan } & 0 ! \\ \text { sindh } & 0 !\end{array}$

Fig 13: Manage province

\section{Conclusion}

Now-a-days everything is getting computerized. Manual work usually consumes a lot of time and is error prone. To make complaining easy and manage crime records this application is very helpful. Thus, Crime Management System overcomes most of the limitations of the existing system along with being very user friendly application.

\section{References}

[1] Steven Holzner, "HTML Black Book", Jon Skeet,"C\# in depth

[2]Shiju Sathyadevan, Crime analysis and prediction,IEEE,25Sept2014,10.1109/CNSC.20 14.6906719 .

[3]Wikipedia-SQL Server Express - https://en.wikipedia.org/wiki/SQL_Server_Expr ess.

[4]Anil Jaiswal, Neeta Gunjal, PoojaLondhe, Shikha Singh, Ramesh Solanki, "Crime Automation \& Reporting System” ,International Journal of Science and Modern Engineering (IJISME), Volume-1, Issue-11, October 2013.

[5] http://en.wikipedia.org/wiki/Criminal_record.

[6] http://thinknext.co.in/rupali/homepage.aspx.

[7] Anil Jaiswal, Neeta Gunjal, PoojaLondhe, Shikha Singh, Ramesh Solanki, "Crime Automation \& Reporting System" ,International Journal of Science and Modern Engineering (IJISME), Volume-1, Issue-11, October 2013. [8] http://topicideas.org/how-to-online-crime-reporting-and-managementsystem-pdf . 